\title{
GENERALIZED HYERS-ULAM STABILITY OF RICCATI DIFFERENTIAL EQUATION
}

\author{
SOON-Mo Jung AND Themistocles M. RASSIAS
}

Abstract. In this paper, we will prove the generalized Hyers-Ulam stability of the Riccati differential equation of the form $y^{\prime}(t)+g(t) y(t)+h(t) y(t)^{2}=k(t)$ under some additional conditions. Some concrete examples will be introduced.

Mathematics subject classification (2000): 26D10, 34A40, $39 \mathrm{~B} 82$.

Key words and phrases: Generalized Hyers-Ulam stability, Riccati differential equation, Bernoulli differential equation.

\section{REFERENCES}

[1] C. Alsina AND R. GER, On some inequalities and stability results related to the exponential function, J. Inequal. Appl. 2 (1998), 373-380.

[2] D. H. HYERS, On the stability of the linear functional equation, Proc. Nat. Acad. Sci. USA 27 (1941), 222-224.

[3] D. H. Hyers, G. IsAC And TH. M. Rassias, Stability of Functional Equations in Several Variables, Birkhäuser, Boston, 1998.

[4] D. H. Hyers AND TH. M. RASsiAs, Approximate homomorphisms, Aequationes Math. 44 (1992), $125-153$.

[5] S.-M. Jung, Hyers-Ulam-Rassias Stability of Functional Equations in Mathematical Analysis, Hadronic Press, Palm Harbor, 2001.

[6] S.-M. Jung, Hyers-Ulam stability of linear differential equations of first order, Applied Math. Letters 17 (2004), 1135-1140.

[7] S.-M. Jung, Hyers-Ulam stability of linear differential equations of first order, III, J. Math. Anal. Appl. 311 (2005), 139-146.

[8] S.-M. Jung, Hyers-Ulam stability of a system of first order linear differential equations with constant coefficients, J. Math. Anal. Appl. 320 (2006), 549-561.

[9] S.-M. JUNG, Hyers-Ulam stability of linear differential equations of first order, II, Applied Math. Letters 19 (2006), 854-858.

[10] S.-M. JUNG AND TH. M. RASSIAS, Ulam's problem for approximate homomorphisms in connection with Bernoulli's differential equation, Appl. Math. Computation, in press. (doi:10.1016/j.amc . 2006.08.120)

[11] T. MiURA, S.-M. Jung AND S.-E. TAKAHASI, Hyers-Ulam-Rassias stability of the Banach space valued linear differential equations $y^{\prime}=\lambda y$, J. Korean Math. Soc. 41 (2004), 995-1005.

[12] T. MiURA, S. MiYAJIMA AND S.-E. TAKAHASI, A characterization of first order linear differential operators, J. Math. Anal. Appl. 286 (2003), 136-146.

[13] TH. M. RASSIAS, On the stability of the linear mapping in Banach spaces, Proc. Amer. Math. Soc. 72 (1978), 297-300.

[14] S.-E. TAKAhasi, T. MiURA AND S. Miyajima, On the Hyers-Ulam stability of the Banach space-valued differential equation $y^{\prime}=\lambda y$, Bull. Korean Math. Soc. 39 (2002), 309-315.

[15] S. M. Ulam, Problems in Modern Mathematics, Wiley, 1964. 